ISBN 978-93-84422-76-9

6th International Conference on Developments in Engineering and Technology

(ICDET-2017)

Bangkok (Thailand) Feb.6-7, 2017

\title{
A Study on Estimating Suitable Site for Securing Water Resources Facility:
}

\section{Focused on the Blue dam}

\author{
Tai Ho Choo ${ }^{1}$, Yong Been Kwon ${ }^{1}$, Su Yong Sim ${ }^{1}$ and Sang Jin Park ${ }^{1}$ \\ ${ }^{1}$ Department of Civil and Environmental Engineering, Pusan National University
}

\begin{abstract}
Industrialization and population growth due to rapid changes in the climate emerging in a big problem. Unfavorable terrain conditions and character of the rain to secure water resources in the case of our country, which is a very important issue. That's why for the used overlapping method about five thematic map using effective new concept of secure water resources through the Blue dam's site suitability analyzed by GIS model. As a result, suitable sites are found and it also has sufficient water resources are secured. Currently, the nation's water resources, to utilize the results of the present paper can solve the problem.
\end{abstract}

Keywords: climate change, overlapping method, securing water resources, site suitability, the Blue dam

\section{Introduction}

Due to industrialization and increases of population growth, rapid changes of the climate are becoming a major problem. Because the temperature of the earth surface increases and results in bad influences, especially global warming, one of the various climate changes, is the most serious problem at publishing reports in the many research centers. According to the report of the 2011 Global Climate America's (2011), average temperature of the earth has risen by $0.8^{\circ} \mathrm{C}$ for the past 100 years because of global warming, and moreover it is increased by $0.6^{\circ} \mathrm{C}$ for 30 years. Also, according to the fourth report of the IPCC (2007), it was reported that abnormal climate is caused by global warming. South Korea is affected by rainfall variation and pattern that caused many problems due to global warming especially. According to the long-term comprehensive plan of water resources (2011-2020) (2011), the average annual precipitation of South Korea is 1,277.4 mm (from 1978 to 2007), about 1.6 times the average rainfall of $807 \mathrm{~mm}$ of the world. However, because of high population density the total annual rainfall per capita is $2,629 \mathrm{~m}^{3}$, which is only $1 / 6$ of the world average $16,427 \mathrm{~m}^{3}$. The available water resource per capita in Korea is $1,553 \mathrm{~m}^{3}$ in 2007 , it classified the water stress country in accordance with PAI standards. To solve these problems, there are various methods securing water resources such as construction of dam and reservoir, modification of operating rule, river filtering, underground dam and co-management of reservoirs or dams. In the present study, we propose a methodology for estimating suitable site of the Blue dam, which can deal with unfavorable topography condition, negative social perception on the construction of dams, the opposition of environmental organization and local residents.

\section{Definition of the Blue dam}

The Blue dam proposed by Choo et al. (2016) is a way of new concept to secure water resources. The basic idea is derived from regulating reservoirs, but there is a clear difference from the approach to them in the opposite concept. Unlike the regulating reservoir which opens and operates the floodgate in flood season, the Blue dam utilizes discharge that flows nonsensically downstream. In other words, the Blue dam has flood reduction effect and it is a structure that provides a water bowl to secure water resources in a basin. The Blue dam is a combination of "Blue" representing clean water and eco-friendly image and "Dam" meaning pond. The location of the Blue dam is set up online in downstream of the existing dam similar to regulating reservoir. The Blue dam and the regulating reservoir is similar, but its function is quite different. Regulating reservoir 
temporarily stores the discharge by peak load power of exiting dam and it discharges evenly downstream. However, the Blue dam not only has function of regulating reservoir but also could secure dam discharge flow rate meaninglessly to downstream in a flood season. In addition, it could protect crops from being damaged by cold water and mitigate flooding damage. In addition, the Blue dam is good for securing ecosystem stability because discharge of ecosystem preservation can uniformly discharge downstream. Also, the Blue dam has many advantages such as power supply through its own power generation and utilization of saved water for recreation (Fig. 1). In the case of South Korea, in particular, it is expected that the Blue Dam can provide the solutions for massive water resource structures that has the opposite of environmental groups and local residents, and social negative perception. Consequently, the Blue dam is expected that it will be a good alternative to secure water resources in the current situation that a dam site is gradually decreasing.

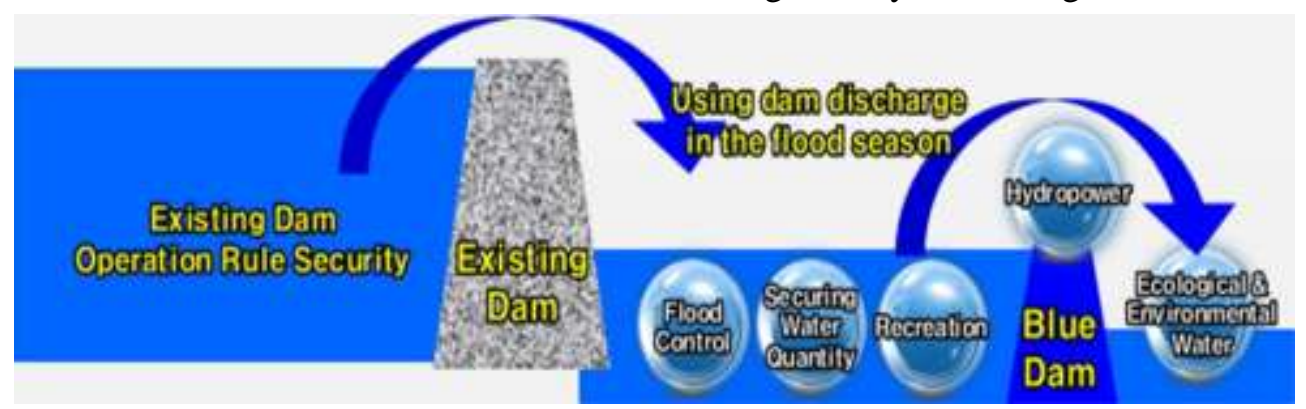

Fig. 1: The functions of the Blue dam (Choo et al., 2016)

\section{Technique of estimating The Blue dam suitable site}

In order to estimate the Blue dam suitable site, river and land cover maps from Water Resources Management Information System (WAMIS), digital elevation map (DEM) from Korea National Spatial Data Infrastructure Portal and hydrogeological map from National Groundwater Information Center have been collected. We proceed and projected spatial information maps using ArcGIS. Then, the Blue dam suitable sites were selected by overlapping each map and calibration (Fig. 2).

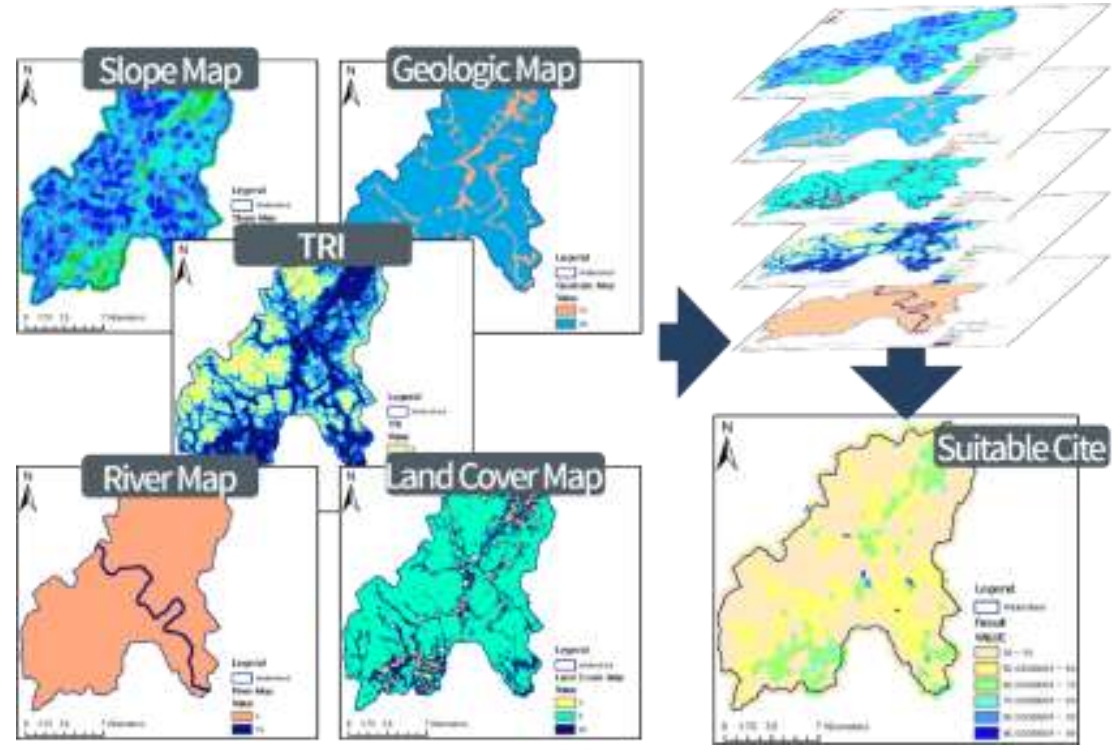

Fig. 2: Weighting for each index and Overlay

\subsubsection{Study area}

The total area of Seomjingangdam downstream watershed is $237.08 \mathrm{~km}^{2}$, and is located at the east longitude between $127^{\circ} 02^{\prime}$ and $127^{\circ} 14^{\prime}$ and north latitude between $35^{\circ} 24^{\prime}$ and $35^{\circ} 35^{\prime}$. The watershed includes 3 cities and counties such as Jeongeup-si, Imsil-gun, and Sunchang-gun. The study area consists of 3 
standard watershed (400201, 400202, 400203). The basic data such as basin and river characteristics, stream order, slope, elevation and soil map on study area were collected.

\subsubsection{Production of thematic map}

To search The Blue dam area, suitable site Analysis was performed using ArcGIS. To estimate suitable site, collected spatial information maps were proceed and projected and then we were converted from original to grid maps with $10 \mathrm{~m}$ by $10 \mathrm{~m}$. Finally, 5 spatial information map such as slope, geologic, river, land cover and topographic maps were overlapped and the suitable The Blue dam site were selected. Each map is as follows.

\subsubsection{Slope map}

The degreed of slope about study area using DEM collected Korea National Spatial Data Infrastructure Portal that has the scale 1:5000 was analyzed. The results of slope map show that the maximum, minimum, mean degree are 47.7, 0, 16.3, respectively (Fig. 3).

\subsubsection{Geological map}

To analyze which geology is the best to build a dam construction, geological analysis on 53 dam sites in South Korea was performed. Metamorphic, half consolidation sedimentary, intrusive igneous, and clastic sedimentary rocks from geologic analysis account for 48, 43.4, 35.5 and 28.8 percent, respectively. Also, porosity forms of rock comprises 90 percent of the insulation. In the present study, because dam secures water resources by blocking runoff flow from ground and underground, we took into account porosity forms of rock shown as Fig. 4.

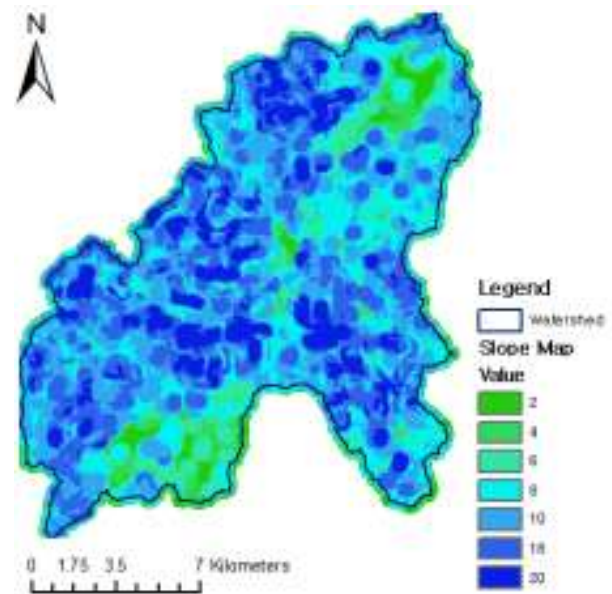

Fig. 3: Slope Map

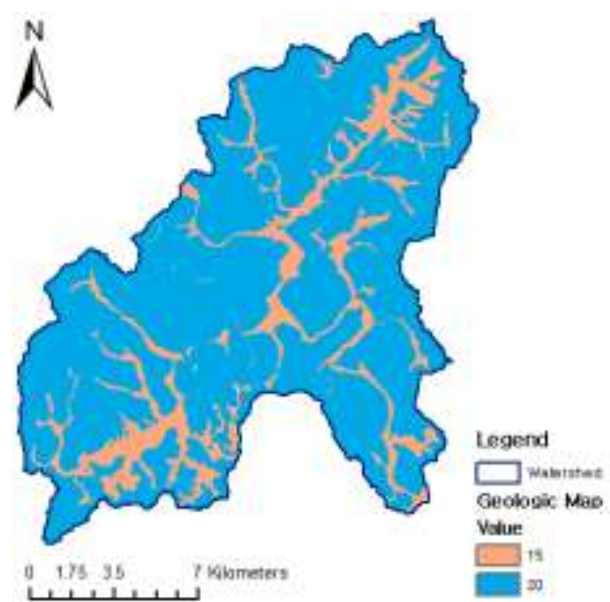

Fig. 4: Geologic Map

\subsubsection{River map}

National, regional rivers and stream order maps were collected from WAMIS and then, these maps are combined to 1 layer as a total river map. Generally, surplus water that exceeds the dam capacity just flows downstream without storage in the flood season meaninglessly. However, the main objective of the Blue dam is securing water resources at dam downstream. Therefore, the Blue dam is commonly constructed directly downstream of a dam such as a multipurpose dam, a water supply dam, or a hydroelectric dam. Fig. 5 was extracted from total river map of study area because the Blue dam is located in a dam downstream directly.

\subsubsection{Land cover map}

Land cover map is generated from satellite image. This map is a highly reliable map because remote sensing data could reflected existing land use. To consider suitable site of the Blue dam, 8 land cover items were classified as stage 3(good, normal, bad). Stage 1(good) consists of forest, wetland and water, stage 3(bad) is urban. Stage 2 are paddy, upland, pasture and barren, reclassified land cover map is shown as Fig. 6. 


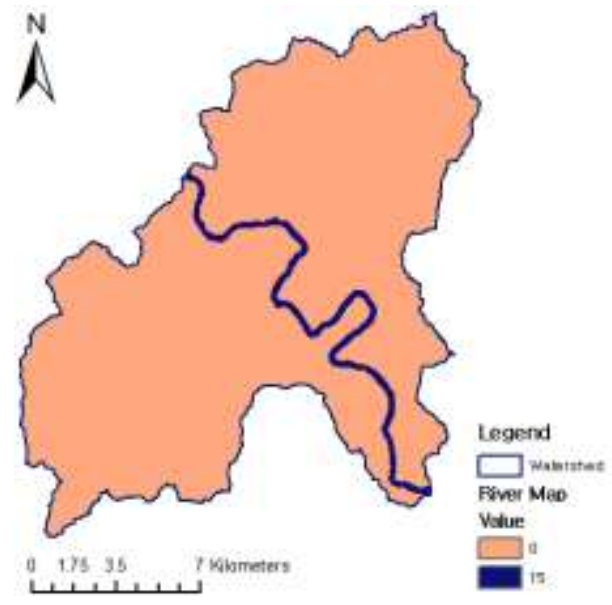

Fig. 5: River Map

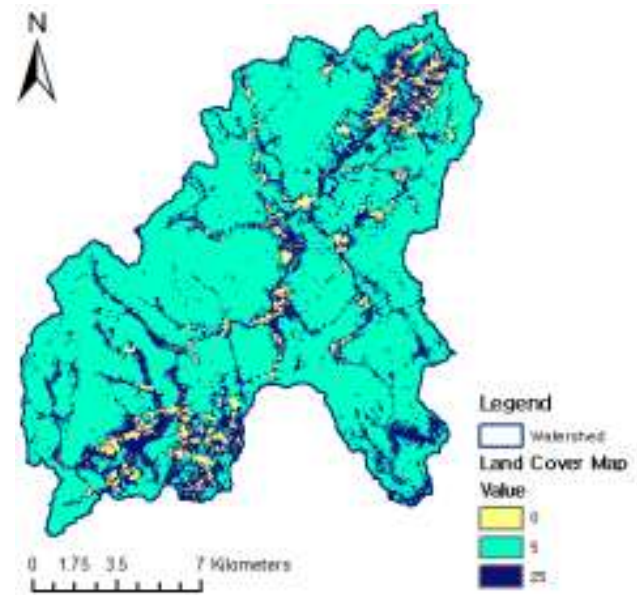

Fig. 6: Land Cover Map

\subsubsection{Topographic map}

To analyze suitable site, in the present study, preceding researches were investigated. We selected TRI (Terrain Roughness/Ruggedness Index) proposed by Riley (1999) to analyze topography and classification of TRI is Table 1 .

\begin{tabular}{lll}
\multicolumn{3}{c}{ TABLE 1: TRI classification by Riley } \\
\hline \hline Classification & TRI value & Reclassify \\
\hline Level & $0-80 \mathrm{~m}$ & Good \\
Nearly level & $81-116 \mathrm{~m}$ & Good \\
Slightly rugged & $117-161 \mathrm{~m}$ & Medium \\
Intermediately rugged & $162-239 \mathrm{~m}$ & Medium \\
Moderately rugged & $240-497 \mathrm{~m}$ & Medium \\
Highly rugged & $498-958 \mathrm{~m}$ & Worst \\
Extremely rugged & $959-4367 \mathrm{~m}$ & Worst \\
\hline \hline
\end{tabular}

\section{Estimation results}

The calibration results of estimating suitable site model were classified into stage $6(33-50,50-60,70-80,80$ 90, 90-100). 90-98, the best score, analyzed 5 suitable sites shown as Fig. 8.

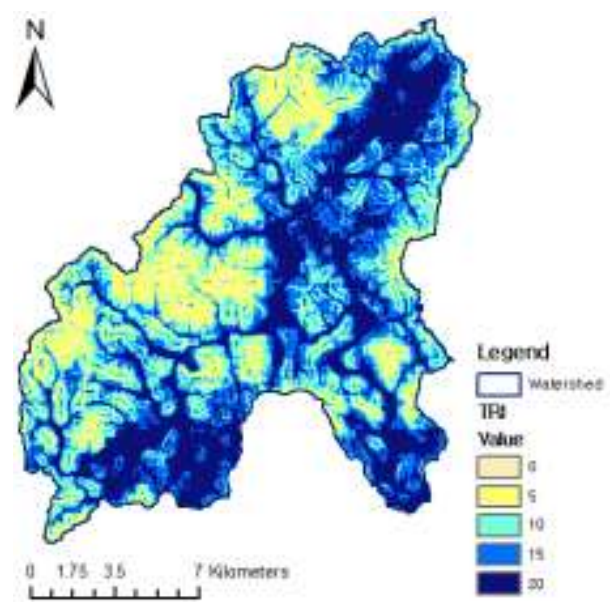

Fig. 7: TRI

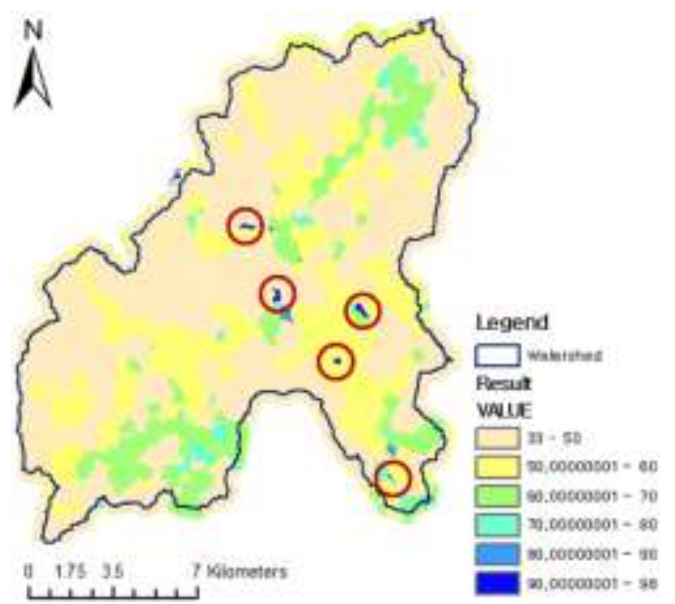

Fig. 8: The results of suitable cite for The Blue dam 


\section{Conclusions}

It is necessary to secure water resources because seasonal variations of rainfall characteristics, topography condition (an east high west low type) and the negative publicity of large civil engineering projects existed in South Korea. Therefore, to make the best use of limited water resources, importance of additional water resources should be required gradually. In the present study, the Blue dam was introduced as a new method of securing water resources. To estimate suitable site of the Blue dam, 5 layers such as slope, geologic, river, land cover and topographic maps for each items were weighted and overlaid.

\section{Acknowledgement}

This research was supported by a grant (11-TI-C06) from Advanced Water Management Research Program funded by Ministry of Land, Infrastructure and Transport of Korean government.

\section{Reference}

[1] IPCC, IPCC Fourth Assessment Report: Climate Change, 2007 (AR4): The Physical Science Basis, Contribution of Working Group I to the Fourth Assessment Report of the Intergovernmental Panel on Climat Change, Cambridge University Press, Cambridge, United Kingdom and New York, NY, USA, 2007.

[2] J. Star and J. E. Estes. Geographic information systems: an introduction. vol. 303. Englewood Cliffs, NJ: Prentice Hall, 1990.

[3] Ministry of Land, Transport and Maritime Affairs, Water Resources Plan (2011 2020), Sejong-Si, 2011.

[4] S. J. Riley, S. D. DeGloria, and R. Elliot, "A terrain ruggedness index that quantifies topographic heterogeneity," in intermountain Journal of sciences, vol. 5, No.1-4, pp. 23-27, 1999.

[5] T. H. Choo, H. C. Yoon, G. S. Yun, Y. B. Kwon, S. Y. Shim and S. K. Chae, "The method of securing water supply resources of existing dam by using The Blue dam," in Journal of Korean Society of Water and Wastewater, vol. 29, No.2, pp. 243-249, 2015.

[6] T. H. Choo, J. Y. Huh, H. C. Yoon, G. S. Yun, and J. K. Son, "Method for new conceptual securing water resources: a case study of the Miryang multipurpose dam in Korea," Environmental Earth Sciences, vol. 75, No.10, pp. 1-18, 2016. https://doi.org/10.1007/s12665-016-5598-1 